\title{
Video games and higher education: what can "Call of Duty" teach our students?
}

\author{
Nick Tannahill' , Patrick Tissington ${ }^{1}$ and Carl Senior ${ }^{2 *}$ \\ 1 Aston Business School, Aston University, Birmingham, UK \\ 2 School of Life and Health Sciences, Aston University, Birmingham, UK \\ *Correspondence: c.senior@aston.ac.uk \\ Edited by: \\ Douglas Kauffman, Univesity of Nebraska-Lincoln, USA \\ Reviewed by: \\ Ya-Shu Yang, University of Nebraska-Lincoln, USA \\ Michael K. Thomas, University of Wisconsin-Madison, USA
}

Here it is argued that with game-based learning it is possible, through their inherent teaching mechanisms, to sustain stimulation throughout a class within higher education. That is, the "net generation" (Tapscott, 1999, p. 6) is intrinsically motivated by games and that commercial video games have a potentially important role in the classroom to assist learning of a range of crucial transferable skills. We further argue that commercial off the shelf (COTS) game design is replete with effective constructivist teaching structures and that such games should play a more prominent role within mainstream education.

As suggested by their title COTS are games that one can purchase on the high street and as such are often overlooked by scholars studying the pedagogic efficacy of bespoke educational gaming environments or serious games. For the student there is value in "edutainment" as an effective learning process that blurs the line between work and play, maintaining initial levels of concentration through the equilibrium of entertainment and education (Ryan et al., 2006). Through an examination of the learning mechanisms found in cognitively motivational and commercially successful video games this commentary will explore "synergy between pedagogy and engagement" (Van Eck, 2006, p. 18) and what such games can offer to the field of education. This commentary will not focus on bespoke software that has enjoyed considerable research attention so far. In doing so it is hoped to open the debate on the utility that COTS have within the classroom.

It is easy to dismiss such video games as commercially driven distractions, but in fact COTS have been linked to increased motivation, more varied learning methodologies, and performance at least equal to that achieved by traditional means, but with greater enjoyment of the learning process itself (Ebner and Hoizinger, 2006; Ryan et al., 2006). The full range of learning mechanisms inherent in game playing has been detailed elsewhere (see Gee, 2007). Here, these approaches have been summarized into a number of overarching and overlapping themes that detail the importance of cognitive stimulation, motivation, constant assessment, and the encouragement of a system style of thinking (see Figure 1). In addition to this, features unique to COTS such as in-game tutorials, challenging levels and eventual boss characters, exist to incentivize the player into a learning process analogous to the educational phases of learning, practice, and assessment, teaching students via what is essentially "the scientific method" (Wright, 2009).

\section{COGNITIVELY STIMULATING}

Playing Electronic Art's "Medal of Honor" or Activision's "Call of Duty" does result with improvements in visual acuity (Green and Bavelier, 2006; Achtman et al., 2008). Further work shows that such games also stimulate at the cognitive level. Take for example the "Tetris effect," a form of hypnagogic imagery resulting from playing Alexey Pajitnov's Tetris that affects the player first during play and continuing to do so when the player is asleep. The elemental shapes (or "Tetriminos") found in Tetris stimulate our visual system to engage in low-level pattern recognition. Players report not only seeing falling Tetriminos in their peripheral vision and while dreaming (Stickgold et al., 2000), but even find themselves attempting to mentally interlock real world objects together (Earling, 1996), the core skill involved in playing the game. Indeed the same study (Stickgold et al., 2000) found that even amnesic participants with extensive bilateral medial temporal lobe damage produced similar reports, despite being unable to recall having played the game. It has also been shown that playing goal directed games such as Activision's "Call of Duty" ensures a release of dopamine in a region of the brain known as the ventral striatum (Koepp et al., 1998) which is an important part of the cortical networks thought to be implicated in the perception of reward (Lega et al., 2011).

\section{MOTIVATING}

Video games constantly incentivize the player with the prospect of being gratified for problem solving (Griffiths, 2002) which has parallels with a well-run small group tutorials where praise or high marks are rewards for problem solving. Whether it be victory over the game's battles, solving a puzzle or the prospect of a better looking character to control, the player is constantly motivated with goal orientation via a "carefully calibrated balance of rewards, challenges, and chance" (Chatfield, 2010, p. 2). Players dislike interruption primarily because it interferes with their learning and odds of success; entertainment is a factor, but it is secondary to successful skill and knowledge development. Ironically then having paid to be entertained the player, quite happily, spends most of their time learning skills to overcome assessment, 


\author{
Alexey Pajitnov \& Vadim Gerasimov, Tetris (Nintendo, Moscow, 1989) [Cognitive Stimulation] \\ Blizzard, World of Warcraft (Blizzard Entertainment, California, 2004) [Motivating] \\ Capcom, Super Street Fighter II Turbo (Capcom, Osaka, 1994) [Cognitive Stimulation] \\ Capcom Production Studio 4, Devil May Cry (Capcom, Osaka, 2001) [Constant Feedback] \\ From Software, Demon's Souls (SCE Japan Studio, Tokyo, 2009) [Failure as a Learning Device] \\ Harmonix, Rock Band (Massachusetts, MTV Games, 2007) [Failure as a Learning Device] \\ Maxis, SimAnt (Maxis, California, 1991) [Systems Thinking] \\ Maxis, SimEarth (Maxis, California, 1990) [Systems Thinking] \\ Maxis, Spore (Maxis, California, 2000) [Systems Thinking] \\ Maxis, The Sims (Maxis, California, 2000) [Systems Thinking] \\ Microprose, Civilisation (Microprose, Maryland, 1991) [Systems Thinking] \\ Nintendo EAD, Big Brain Academy: Wii Degree (Nintendo, Kyoto, 2007) [Motivating] \\ Nintendo EAD, SimCity (Kyoto, Nintendo, 1991) [Systems Thinking] \\ Nintendo EAD, Super Mario Bros Wii (Kyoto, Nintendo, 2009) [Motivating] \\ Nintendo SDD, Brain Age (Nintendo, Kyoto, 2006) [Motivating] \\ Origin Systems, Ultima Online (Electronic Arts, Texas, 1997) [ Motivating] \\ Sports Interactive, Football Manager (SEGA, London, 2005) [Systems Thinking] \\ Treyarch, Call of Duty (Activision Blizzard, California, 2011) [Cognitive Stimulation] \\ Electronic Arts, Medal of Honour (Electronic Arts, Canada, 2010) [Cognitive Stimulation]
}

FIGURE 1 |A summary compendium of various COTS with the learning themes that each game best fits within indicated in the square brackets.

working toward optional personal goals, and compulsory ones set by the game designer.

It goes without saying that persistent motivation and goal-orientation are characteristics sought after by most students, the latter of which is no better demonstrated than with the example of Ultima Online. In this massively multiplayer online game (MMO) hundreds of thousands of players play together online in real time, both cooperatively and competitively to develop their virtual characters. Players work on their skills and acquire in-game wealth either through trade, force, or in some cases, much like in real life, a mix of both. Johnson cites the example of Troy Stolle, a construction site worker from Indianapolis who, having spent all day at his "bone-jarringly repetitive work with hammer and nails" (2006, p. 27), would come home to Ultima Online and repeat essentially the same process in a virtual world. Stolle's character, nicknamed "Nils Hansen," was a Grandmaster Blacksmith, a title that took him 6 months of smithing to achieve. Smithing in Ultima Online involves clicking one's mouse cursor on virtual hillsides to mine ore, traveling a few minutes to the forge to click virtual ore into ingots, and yet more clicking to turn said ingots into weapons and armor. Making the process even more time-consuming, each time any of these processes, which can fail outright, take place the output can produce high or low quality material, the latter of which is often worthless and thus scrapped.

Playing these games is like "having a part-time job - only instead of getting paid, it costs you money" (Johnson, 2006, p. 27). Stolle was replacing his physical hammer and nail with a virtual hammer and anvil, and paying \$9.95 a month to do so; he was also, albeit perhaps unwittingly, gaining transferable employability skills in the process, such as product management and an acute sensitivity to both the in-game economy and his customer base (see, e.g., Senior and Cubbidge, 2010).

\section{CONSTANTLY PROVIDING FEEDBACK}

Commercial off the shelf games are all about "delayed gratification" (Johnson, 2006, p. 28) which is granted only when the player's skill and consistency has been assessed and deemed sufficient to proceed to the next, inevitably harder stage of assessment. Capcom's "Devil May Cry" is a case in point, employing a letter grading system that evaluates player performance dynamically, providing feedback by modeling the results of the player's decisions. Rather than evaluating player performance only at the end of a gaming period, nearly a quarter of the display is at all times dedicated to a dynamic grading system which ranks the player's understanding of the game mechanics based on their performance. Should the player execute a varied and effective gameplay strategy that demonstrates an understanding of all they have been taught, their rank will rise through $\mathrm{D}, \mathrm{C}, \mathrm{B}$, and A-S, the equivalent of an A+. Should the player's successful execution of their strategy be countered and their educative state of "flow" (Csíkszentmihályi, 1992, p. 8) interrupted this rank is reset back to $D$. This assessment is compiled at the end of each level in the form of a report, providing the player with an overview of their performance, individually ranking elements of gameplay such as speed and efficiency, as well as assigning an overall grade.

This kind of dynamic feedback sits in contrast to that of traditional education, which tends to follow a modular based structure and is delivered "in big, ugly, rather unpleasant lumps" (Chatfield, 2010, p. 2) that presents a relatively limited picture of student progress. The relevance to education then is that, as teaching devices, games can constantly and automatically assess the learner's ability from the moment they start playing to the moment they stop; this is a promise that few other pedagogic tools can truly deliver on. 


\section{ENSURING FAILURE IS USED AS A LEARNING DEVICE}

Probably the most common source of failure for students is failing to engage with a task in the first place. Video games bypass this personal barrier by adhering to the principle of "low cost of failure and high reward for success” (Gee, 2007, p. 59). Players choose to escape the game worlds, despite the fact that they constantly and bluntly assess their efforts, because they are incentivized through failure as much as through reward; "the fastest way to winning is through losing, since each loss is a learning experience" (Frand, 2000, p. 17). Take for example, Harmonix's "Rock Band," which like "Devil May Cry," is another game that constantly assesses skill. The game gages players' success rate as a percentage which improves each time. What keeps players interested is that failure occurs so often that it is effectively redefined as temporary, your efforts redeemable and improving with each attempt; failure is a reality, but it is one without consequences significant enough to deter your learning (Gee, 2007).

This redefinition of failure avoids a common pitfall of edutainment; sacrificing challenge in an attempt to keep the player entertained. Here, the learning process delivers on both fronts while at times it is challenging, it is rarely disenchanting for the learner. Success, however illusive, never seems out of reach because the relatively low cost of failure brings the two concepts much closer together, making them less polar and absolute. Even in the event of success player achievement is qualified, with a percentage often in the 80 s or 90 s. Due to the low cost of failure we are encouraged to strive for perfection, rather than being content with a minimum pass mark, reminding us that we have not won, but rather "failed better" (Chatfield, 2010).

\section{ENCOURAGING SYSTEMS THINKING}

Wright's "SimCity" might not teach players what single-handedly running a bustling metropolis is like in real life but what it does teach is how different variables within a system interact in emergent and complex ways (Chatfield, 2010). As a result, the player learns to instinctively view the situation in front of them, be it real or virtual, as a whole and as such can micromanage accordingly. They see each immediate task as part of a much larger system with numerous different, interacting variables at play, developing their own mental model in order to introduce order to something that is otherwise chaotic. This is significant because at present educational programs are striving to offer the learner content that is both dynamic and interactive (Corlett, 1965). The capacity of video games to scale their cultural models to micro or macro levels and the dynamic nature of their content arguably makes them more indicative of, and relevant to, the world outside the classroom. This process is hugely incentivizing in that it allows and encourages players to constantly gage their progress, reminding them of where they've come from, what they're striving toward, and how close they are to achieving it (see, e.g., Stuart, 2011).

Despite their challenging sophistication, themes and game mechanics and an audience with supposedly low attention spans COTS sell in the millions (Swing et al., 2010). Players of all ages are willing to "reverse-engineer these complex models to understand what is under the hood of a game" (Wright, 2009). These games have the potential to demonstrate a "synergy between pedagogy and engagement" (Van Eck, 2006, p. 18). At the very least, the prospective benefits of game-based learning provide us with reason to examine our fear of diluting the aims of education by introducing elements of entertainment. Educators can and should take advantage of the untapped resources with COTS to establish contemporary pedagogy that is exciting, interesting, and relevant for the modern day student.

\section{REFERENCES}

Achtman, R. L., Green, C. S., and Bavelier, D. (2008).Video games as a tool to train visual skills. Restor. Neurol. Neurosci. 26, 435-446.

Chatfield, T. (2010). Why Games are the 21st Century's Most Serious Business. London: The Royal Society for the Encouragement of Arts.

Corlett, E. N. (1965). Some problems of management education in Britain and a proposed solution. Manage. Int. 5, 53-56.

Csíkszentmihályi, M. (1992). Flow: The Psychology of Optimal Experience. Cambridge: Cambridge University Press.

Earling, A. (1996). The tetris effect: do computer games fry your brain? Philadelphia Citypaper. Available at: http://archives.citypaper.net/articles/032196/article038.shtml (accessed March 21-28).

Ebner, M., and Hoizinger, A. (2006). Successful implementation of user-centered game based learning in higher education: an example from civil engineering. Comput. Educ. 49, 873-890.

Frand, J. L. (2000). The information age mindset. Educause Rev. 35, 15-24.

Gee, J. P. (2007). What Video Games Have to Teach us About Learning and Literacy. Basingstoke: Palgrave Macmillan.

Green, C. S., and Bavelier, D. (2006). Effect of action video games on the spatial distribution of visuospatial attention. J. Exp. Psychol. Hum. Percept. Perform. 32, 1465-1478.

Griffiths, M. (2002). The educational benefits of videogames. Educ. Health 20, 47-51.

Johnson, S. (2006). Everything Bad is Good for You. London: Penguin Press.

Koepp, M. J., Gunn, R. N., Lawrence, A. D., Cunningham, V. J., Dagher, A., Jones, T., Brooks, D. J., and Grasby, P. M. (1998). Evidence for striatal dopamine release during a video game. Nature 21, 266-268.

Lega, B. C., Kahana, M. J. B., Jaggi, J., Baltuch, G. H., and Zaghoul, K. (2011). Neuronal and oscillatory activity during reward processing in the human ventral striatum. NeuroReport 22, 795-800.

Ryan, R., Rigby, S., and Przybylski, A. (2006). The motivational pull of video games: a self-determination theory approach. Motiv. Emot. 30, 344-360.

Senior, C., and Cubbidge, R. (2010). Enhancing employability in the "ME generation." Educ. Train. 52, 445-449.

Stickgold, R., Malia, A., Maguire, D., Roddenbury, D., and O'Connor, M. (2000). Replaying the game: hypnagogic images in normals and amnesics. Science 290,350-353.

Stuart, K. (2011). The seduction secrets of video game designers. The Guardian. Available at: http://www. guardian.co.uk/technology/2011/may/15/videogame-design-psychology (Sunday 15th May).

Swing, E. L., Gentile, D. A., Anderson, C. A., and Walsh, D.A. (2010). Television and video game exposure and the development of attention problems, Pediatrics 126, 214-221.

Tapscott, D. (1999). Educating the net generation. Educ. Leadersh. 56, 6-11.

Van Eck, R. (2006). Digital game-based learning: it's not just the digital natives who are restless. Educause Rev. 41, 17-30.

Wright, W. (2009). A Conversation with Will Wright, Keynote Lecture at the Web 2.0 Expo. New York: Javits Centre.

Received:09March 2012; accepted:06 June 2012; published online: 25 June 2012.

Citation: Tannahill N, Tissington P and Senior C(2012) Video games and higher education: what can "Call of Duty" teach our students? Front. Psychology 3:210. doi: 10.3389/ fpsyg.2012.00210

This article was submitted to Frontiers in Educational Psychology, a specialty of Frontiers in Psychology. Copyright () 2012 Tannahill, Tissington and Senior. This is an open-access article distributed under the terms of the Creative Commons Attribution Non Commercial License, which permits non-commercial use, distribution, and reproduction in other forums, provided the original authors and source are credited. 